\title{
A Molecular Nanotube with Three-Dimensional $\pi$-Conjugation**
}

\author{
Patrik Neuhaus, Arjen Cnossen, Juliane Q. Gong, Laura M. Herz, and Harry L. Anderson*
}

\begin{abstract}
A $\pi$-conjugated twelve-porphyrin tube is synthesized in $32 \%$ yield by a template-directed coupling reaction that joins together six porphyrin dimers, forming twelve new $C-C$ bonds. The nanotube has two bound templates, enclosing an internal volume of approximately $4.5 \mathrm{~nm}^{3}$. Its $U V / V i s / N I R$ absorption and fluorescence spectra resemble those of a previously reported six-porphyrin ring, but are red-shifted by approximately $300 \mathrm{~cm}^{-1}$, reflecting increased conjugation. Ultrafast fluorescence spectroscopy demonstrates extensive excited-state delocalization. Transfer of electronic excitation from an initially formed state polarized in the direction of the nanotube axis ( $z$ axis) to an excited state polarized in the $x y$ plane occurs within $200 \mathrm{fs}$, resulting in a negative fluorescence anisotropy on excitation at $742 \mathrm{~nm}$.
\end{abstract}

$T_{\text {he synthesis of } \pi \text {-conjugated belts, barrels, and tubes has }}$ become a focus of intense interest. ${ }^{[1-4]}$ Increasing the dimensionality of a $\pi$-system is expected to enhance the electronic delocalization, ${ }^{[5]}$ perhaps leading to exotic cooperative electronic phenomena, such as Aharonov-Bohm oscillations, ${ }^{[6,7]}$ which occur in single-walled carbon nanotubes (CNTs), but have not yet been detected in molecular materials. The bottom-up "total synthesis" of structurally defined CNTs or analogous structures could bring many technological benefits, because CNTs have highly desirable optoelectronic properties. However, the current methods for preparing them yield mixtures of species with different chiralities, diameters, and lengths, resulting in broad distributions of properties. ${ }^{[8]}$ Recent efforts towards the rational chemical synthesis of

[*] Dr. P. Neuhaus, ${ }^{[+]}$Dr. A. Cnossen, ${ }^{[+]}$Prof. H. L. Anderson Department of Chemistry

University of Oxford, Chemistry Research Laboratory

Oxford, OX1 3TA (UK)

E-mail: harry.anderson@chem.ox.ac.uk

Homepage: http://hla.chem.ox.ac.uk/

J. Q. Gong, Prof. L. M. Herz

Department of Physics

University of Oxford, Clarendon Laboratory

Parks Road, Oxford, OX1 3PU (UK)

$\left.{ }^{+}\right]$These authors contributed equally to this work.

[**] We thank the EPSRC and the ERC (grant 320969) for support, the EPSRC Mass Spectrometry Facility in Swansea for mass spectra, and Martin D. Peeks for assistance with molecular mechanics and DFT calculations. P.N. acknowledges a Feodor Lynen Research Fellowship from the Alexander von Humboldt Foundation and a Marie Curie Individual Fellowship (PIEF-GA-2011-301336).

0 Supporting information for this article is available on the WWWW under http://dx.doi.org/10.1002/anie.201502735.

of (c) 2015 The Authors. Published by Wiley-VCH Verlag GmbH \& Co. $\mathrm{KGaA}$. This is an open access article under the terms of the Creative Commons Attribution License, which permits use, distribution and reproduction in any medium, provided the original work is properly cited.
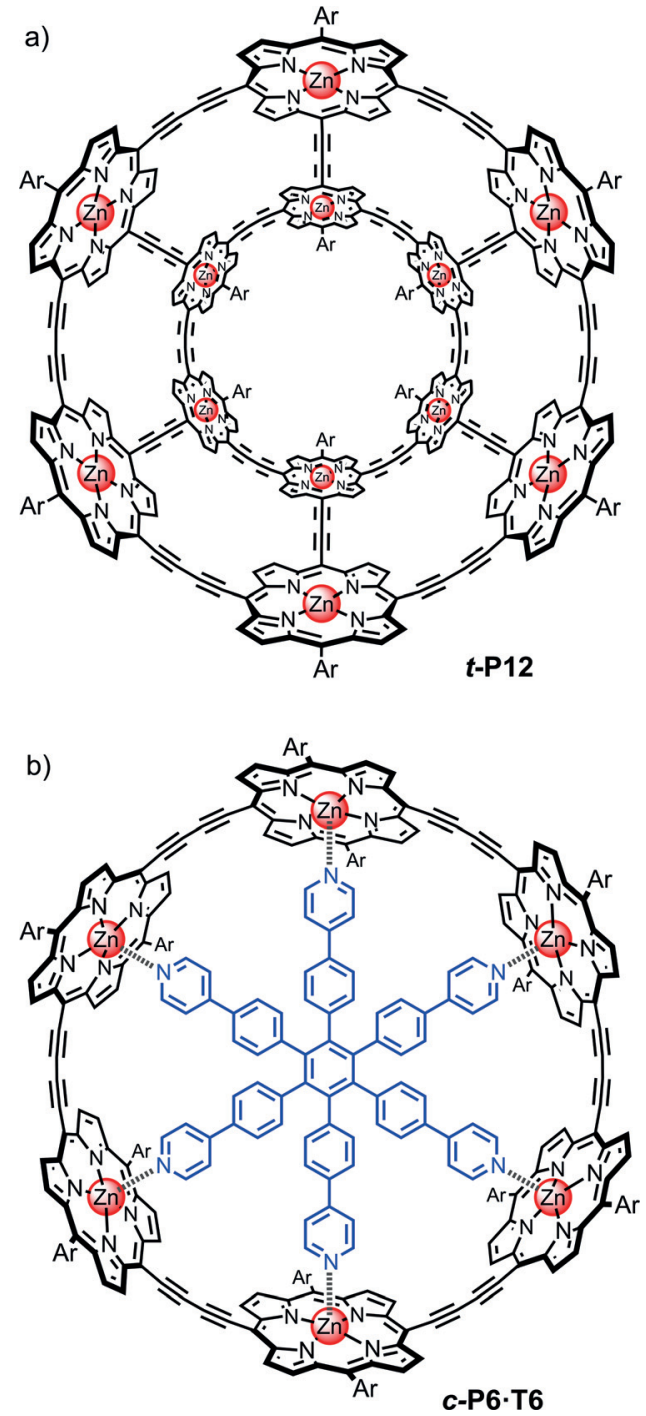

Figure 1. Structures of the twelve-porphyrin tube $t-P 12$ (a) and the previously reported six-porphyrin nanoring template complex c-P6.T6 (b).$^{[12]}$

CNTs focused on the use of cycloparaphenylenes as precursors or templates. ${ }^{[1-3,9-11]}$ Herein, we present the synthesis and photophysical behavior of a discrete molecular tube $\boldsymbol{t}$-P12 (Figure 1a), consisting of twelve porphyrins, each of which is directly $\pi$-conjugated to its three neighbors. This tube can be viewed as a rim-to-rim dimer of the cyclic porphyrin hexamer $\boldsymbol{c}$-P6, shown as its complex with the T6 template in Figure $1 \mathrm{~b} ;{ }^{[12]} \boldsymbol{t}$-P12 is also obtained as a template complex, $\boldsymbol{t}$-P12.(T6) $)_{2}$, with the geometry of a hexagonal prism. A wide variety of synthetic molecular and supramolecular prisms and nanotubes have been reported previously, ${ }^{[13-19]}$ but these 


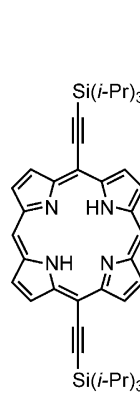

P1a

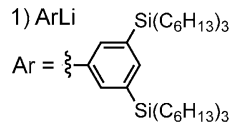

then $\mathrm{H}_{2} \mathrm{O}, \mathrm{DDQ}(76 \%)$

2) $\mathrm{Zn}(\mathrm{OAc})_{2}(98 \%)$ 3) NBS $(56 \%)$

4) $\mathrm{Me}_{3} \mathrm{SiC}_{2} \mathrm{H}$

$\mathrm{Pd}_{2} \mathrm{dba}_{3}, \mathrm{PPh}_{3}$,

Cul, $i-\mathrm{Pr}_{2} \mathrm{NH}(100 \%)$

5) $\mathrm{K}_{2} \mathrm{CO}_{3}, \mathrm{MeOH}(98 \%)$

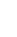
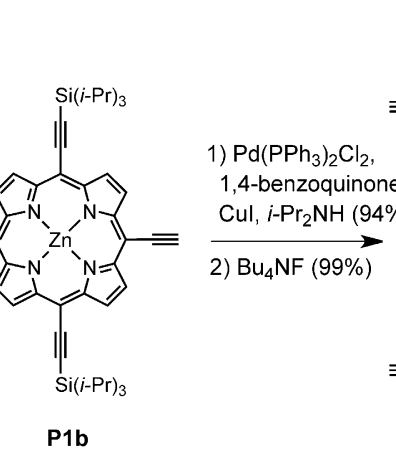
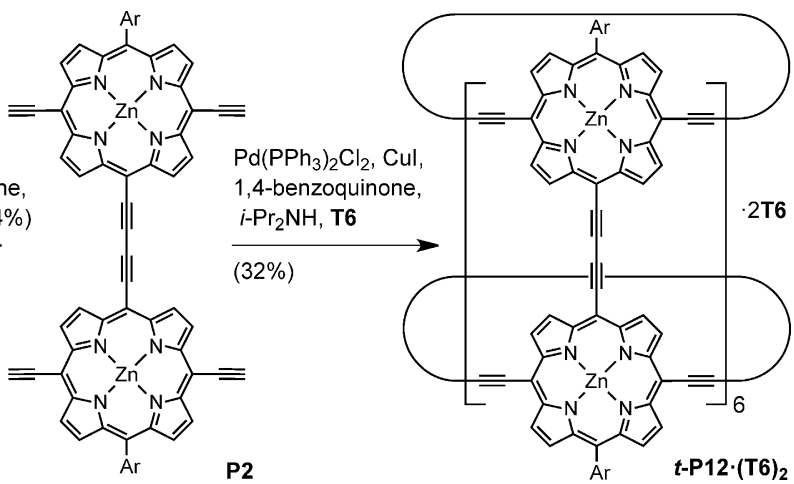

Scheme 1. Synthesis of porphyrin nanotube $t-\mathrm{P} 12 \cdot(\mathrm{T} 6)_{2} . \mathrm{dba}=$ dibenzylideneacetone, $\mathrm{DDQ}=2,3$-dichloro-5,6-dicyanobenzoquinone, NBS $=$ $\mathrm{N}$-bromosuccinimide.

structures lacked a $\pi$-conjugated cylindrical surface. Cobalt porphyrins have been polymerized on CNT templates to give a material with some similarity to $\boldsymbol{t}$-P12, although that polymer had a poorly defined multilayer structure. ${ }^{[20]}$ The monodisperse tube $\boldsymbol{t}$-P12 can be prepared by templatedirected synthesis from a readily accessible porphyrin dimer. This work is a significant step towards the bottom-up synthesis of longer well-defined $\pi$-conjugated nanotubes.

The porphyrin nanotube $\boldsymbol{t}$-P12.(T6) $\mathbf{2}_{\mathbf{2}}$ was synthesized as shown in Scheme 1. The key intermediate is a $5,15-\mathrm{A}_{2} \mathrm{BC}$ porphyrin, P1b, which was prepared from $\mathbf{P 1} \mathbf{a}^{[21]}$ using a Senge arylation ${ }^{[22]}$ to introduce a bulky solubilizing group, followed by metalation with zinc, bromination at the remaining free meso position, Sonogashira coupling with trimethylsilylacetylene, and selective removal of the TMS group. Palladium-catalyzed homo-coupling of P1b followed by removal of the four triisopropylsilyl groups gave the precursor $\mathbf{P 2}$ for cyclo-oligomerization to form $\boldsymbol{t}$-P12.(T6)

When we planned the route shown in Scheme 1, it was not clear whether the final step would be feasible. In this step, six molecules of porphyrin dimer $\mathbf{P 2}$ are brought together by two T6 templates to form $\boldsymbol{t}$-P12. It is known that butadiyne-linked zinc porphyrin dimers such as $\mathbf{P 2}$ bind T6 to form 3:1 complexes of the type $(\mathbf{P 2})_{3} \cdot \mathbf{T} 6{ }^{[12]}$ which would have the wrong spatial arrangement to form $\boldsymbol{t}$-P12 (Scheme 2). The 6:2 complex, (P2) $\left.\mathbf{6}_{\mathbf{6}} \cdot \mathbf{T 6}\right)_{2}$, with the correct arrangement for tube formation is entropically disfavored relative to (P2) $)_{3} \cdot \mathbf{T 6}$, although repulsion between the bulky aryl substituents may

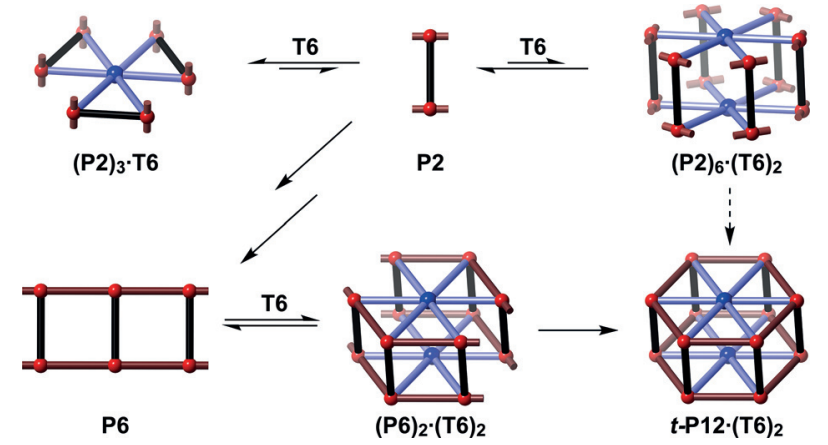

Scheme 2. Mechanisms for the formation of $t$-P12.(T6 $)_{2}$ from dimer P2. destabilize $(\mathbf{P 2})_{3} \cdot \mathbf{T 6}$ relative to $(\mathbf{P 2})_{6} \cdot(\mathbf{T 6})_{2}$. We envisioned that coupling of $\mathbf{P 2}$ molecules would give short belt-like oligomers (such as $\mathbf{P 6}$ in Scheme 2), which would bind to the template in the correct orientation to form the $\boldsymbol{t}$-P12 nanotube. In practice, this template-directed coupling reaction was remarkably efficient, as is shown by the GPC chromatogram of the crude reaction mixture (Figure $2 \mathrm{a}$ ); the desired product
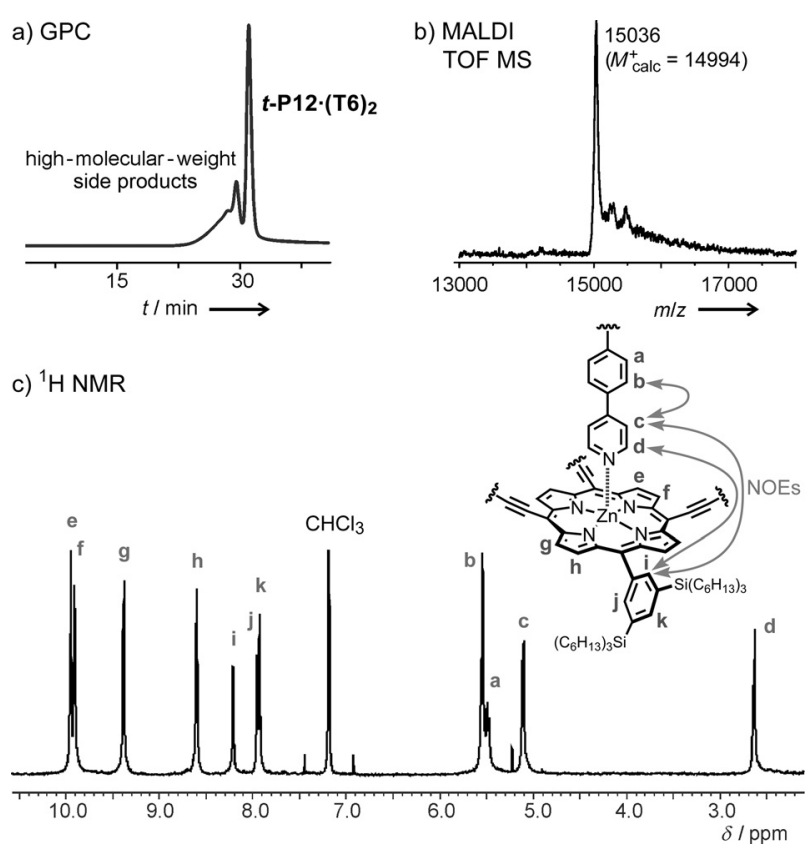

Figure 2. Characterization of $t-\mathrm{P} 12 \cdot(\mathrm{T} 6)_{2}$ : a) GPC chromatogram $(529 \mathrm{~nm})$ of the crude reaction mixture. b) MALDI-TOF spectrum. c) Partial ${ }^{1} \mathrm{H}$ NMR spectrum $\left(400 \mathrm{MHz}, \mathrm{CDCl}_{3}\right)$ showing selected NOEs.

is the dominant peak, and $\boldsymbol{t}$-P12.(T6) $)_{2}$ was isolated in $32 \%$ yield, in a reaction involving the formation of twelve new $\mathrm{C}-\mathrm{C}$ bonds. The 24 trihexylsilyl groups on the rims of the nanotube provide excellent solubility in solvents such as chloroform, and the compound was readily characterized by mass spectrometry (MALDI-TOF) and NMR spectroscopy (Figure 2). 
The ${ }^{1} \mathrm{H}$ NMR spectrum of $\boldsymbol{t}$-P12.(T6) ${ }_{2}$ is strikingly simple for a molecule of its size owing to the $D_{6 h}$ symmetry. The assignment of the aromatic protons shown in Figure $2 \mathrm{c}$ is supported by COSY and NOESY spectra (see the Supporting Information), including the observation of NOEs from proton $\mathrm{d}$ of the template to protons $\mathrm{i}, \mathrm{g}$, and $\mathrm{h}$ of the porphyrin. The signals from the template are strongly shielded by the porphyrin ring currents. There are two signals for the protons of the aryl side groups that are ortho to the porphyrin (proton $i$ and j, Figure $2 \mathrm{c}$ ) because the inside and the outside of the tube provide different environments. The NMR data are consistent with the geometry of $\boldsymbol{t}$-P12.(T6) $)_{2}$ from molecular mechanics calculations (Figure $3 \mathrm{a}$ ), and the dimensions of the

a)

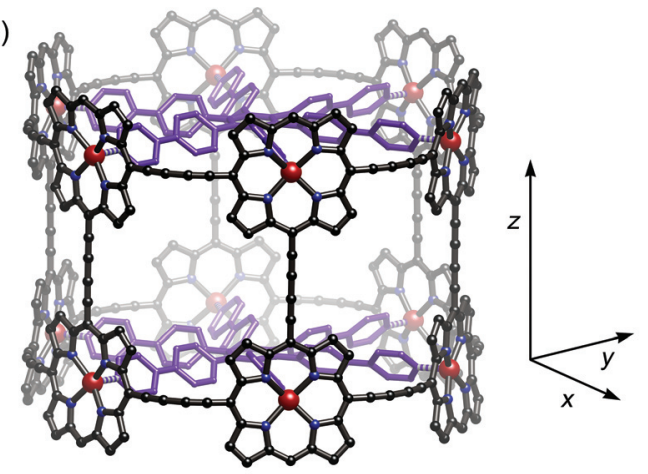

b)
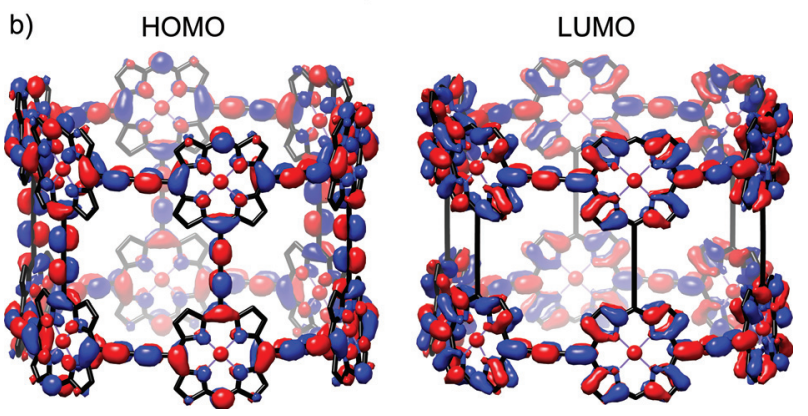

Figure 3. a) Calculated structure of $t$-P12.(T6 $)_{2}$ with hydrogen atoms and aryl groups bearing solubilizing side chains omitted (modified MM2 force field; see the Supporting Information for details), showing the axes used to discuss the fluorescence anisotropy. b) HOMO and LUMO of $t-P 12$ calculated at the BLYP/6-31G(d) level of theory shown with a density isovalue of 0.008 . (Aryl groups were omitted to simplify these calculations.)

tube can be compared with crystal structures of its components. ${ }^{[12 b, 23]}$ The $\mathrm{Zn}-\mathrm{Zn}$ diameter of the tube is $2.43 \mathrm{~nm}$, and the distance between the two T6 templates is $1.35 \AA$, resulting in an internal cavity volume of approximately $4.5 \mathrm{~nm}^{3}$. The length of the nanotube is $2.3 \mathrm{~nm}$ measured to the van der Waals surfaces of the outer $\beta$-pyrrole hydrogen atoms, or $3.2 \mathrm{~nm}$ measured to the para hydrogen atoms of the aryl groups. Although the length of $\boldsymbol{t}$-P12 is very short when compared with a CNT, to the best of our knowledge, it is longer than all previously synthesized $\pi$-conjugated molecular belts, barrels, or nanotubes. ${ }^{[1-4]}$

The UV/Vis/NIR absorption and fluorescence spectra of $\boldsymbol{t}$-P12-(T6) $)_{2}$ are compared with those of $\boldsymbol{c}$-P6.T6 in Figure 4. Both compounds show similar split absorption and emission

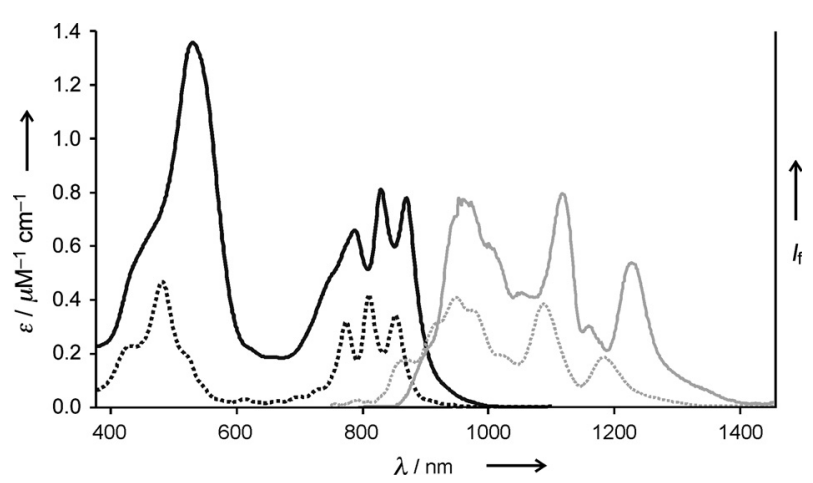

Figure 4. UV/Vis/NIR absorption (black) and fluorescence (gray) spectra of $t$-P12.(T6) ${ }_{2}$ (continuous line) and $c$-P6.T6 (dashed) recorded in chloroform.

bands, indicating that they have similar electronic structures, with emission from a dipole-forbidden first excited state becoming partially allowed through Herzberg-Teller coupling with higher excited states. ${ }^{[12 b]}$ The absorption and emission maxima of $\boldsymbol{t}$-P12.(T6) $)_{2}$ are red-shifted by approximately $300 \mathrm{~cm}^{-1}$ relative to those of $\boldsymbol{c}$-P6-T6, reflecting the greater conjugation in the larger $\pi$-system. DFT calculations (BLYP/ 6-31G(d)) indicate that the HOMO of $\boldsymbol{t}$-P12.(T6) $)_{2}$ is distributed over the entire $\pi$-system (Figure $3 b$ ) whereas the LUMO is spread over both rings, with negligible coefficients on the butadiyne "staves" connecting the two rings in the $z$ direction. Comparison of these frontier orbitals with the four Gouterman orbitals of a simple porphyrin unit shows that the HOMO and LUMO of $\boldsymbol{t}$-P12 are derived from the $\mathrm{a}_{2 u}$ and $\mathrm{e}_{\mathrm{gx}}$ orbitals of the monomer, respectively, ${ }^{[24]}$ which explains the presence of a node along each stave in the LUMO.

Ultrafast time-resolved fluorescence spectroscopy reveals strong coupling between the components of the nanotube. Figure 5 a shows the fluorescence dynamics of $t$-P12.(T6) excited at $830 \mathrm{~nm}$ and $742 \mathrm{~nm}$, with excitation polarized perpendicular or parallel to the detection polarization. The time-dependent fluorescence anisotropies $(\gamma)$ at these two wavelengths, derived from the data in Figure 5 a, show no change over $0-15$ ps after excitation (Figure $5 \mathrm{~b}$ ). The average anisotropy on excitation at $830 \mathrm{~nm}$ is 0.07 , which is similar to that recorded for $\boldsymbol{c}-\mathbf{P 6} \cdot \mathbf{T} \mathbf{6}^{[12 b, 25]}$ and close to the theoretical value of 0.1 for an excited state delocalized over a twodimensional ring. ${ }^{[26]}$ This indicates that in $\boldsymbol{t}$-P12.(T6) ${ }_{2}$, absorption at $830 \mathrm{~nm}$ is associated with transition dipoles in the plane of the six-porphyrin rings ( $x y$ plane, Figure 3 ), and that emission occurs from an excited state that is delocalized over this same $x y$ plane. However, at shorter excitation wavelengths, the anisotropy decreases, becoming negative and reaching a value of -0.04 at $742 \mathrm{~nm}$, whereas the fluorescence anisotropy of $\boldsymbol{c - P 6 \cdot T 6}$ is independent of the wavelength (Figure $5 \mathrm{c}$ ). The most likely explanation for this behavior is that at $742 \mathrm{~nm}$, light is absorbed by transitions associated with the $z$-polarized butadiyne-linked porphyrin dimer staves of the barrel to former higher excited states that emit from the $x y$-polarized state. This interpretation is supported by the observation that porphyrin dimer $\mathbf{5 a}$ has a Q band at $705 \mathrm{~nm}$ and by the report that a related square 


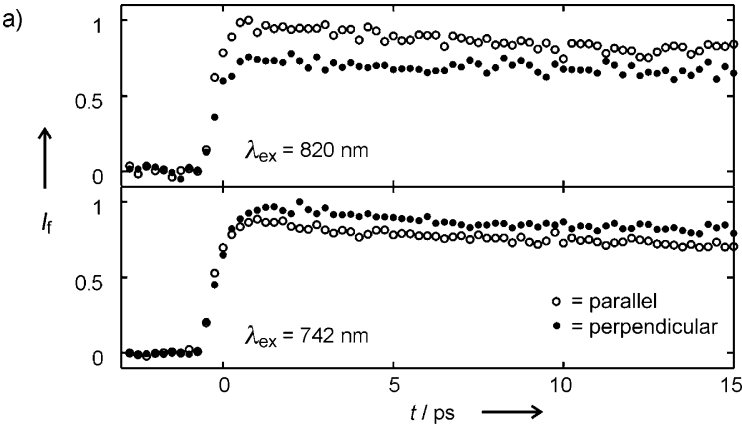

b)

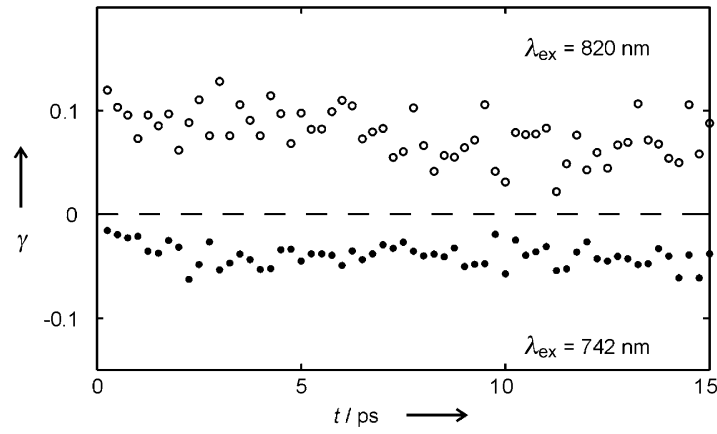

c)

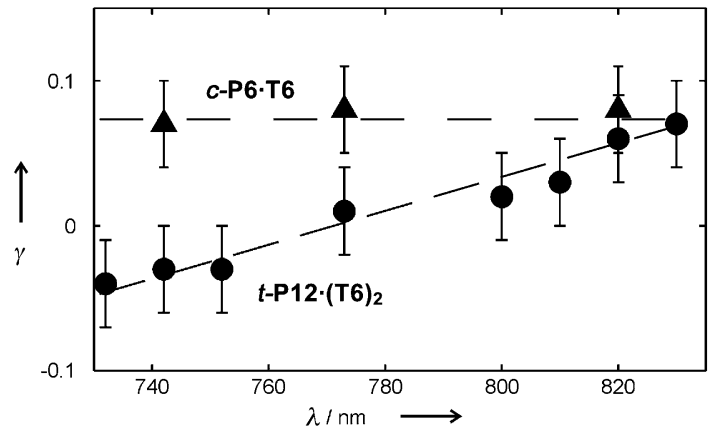

Figure 5. a) Time-resolved fluorescence decay for $t-\mathrm{P} 12 \cdot(\mathrm{T} 6)_{2}$ on excitation at $820 \mathrm{~nm}$ and $742 \mathrm{~nm}$. Samples are excited by a pulse polarized either parallel $(\bigcirc)$ or perpendicular $(\bullet)$ to the detection polarization, with detection at $941 \mathrm{~nm}$. b) Fluorescence anisotropy dynamics for excitation at $820 \mathrm{~nm}(\bigcirc)$ and $742 \mathrm{~nm}(\bullet)$, calculated from the data in (a). c) Fluorescence anisotropy for $t$-P12.(T6 ${ }_{2}$ and $c$-P6-T6 measured over a range of excitation wavelengths (with dashed lines as guides to the eye).

butadiyne-linked porphyrin tetramer exhibits a dimer-like absorption spectrum (Q band at $659 \mathrm{~nm}) .{ }^{[27]}$ If the absorption by $\boldsymbol{t}$-P12.(T6) $)_{2}$ at $742 \mathrm{~nm}$ were entirely $z$-polarized, with emission entirely from a state polarized in the $x y$ plane, then the anisotropy would be $-0.2 .^{[28]}$ The value of -0.04 reflects the presence of overlapping bands at $742 \mathrm{~nm}$, with different polarizations. Migration of electronic excitation from the $z$-polarized staves to the $x y$-polarized state takes place faster than the $200 \mathrm{fs}$ time resolution of our experiment.

In summary, we have synthesized a fully $\pi$-conjugated three-dimensional porphyrin nanotube in $32 \%$ yield by an alkyne homo-coupling reaction involving the formation of twelve new $\mathrm{C}-\mathrm{C}$ bonds. The preparation of this nanotube represents a surprising new type of cooperative templatedirected synthesis, in which the binding mode of the templates switches as the reaction progresses; this contrasts with other types of cooperative template-directed syntheses in which the templates assemble the starting materials in the correct geometry for product formation. ${ }^{[29]}$ The absorption and emission spectra of the nanotube are red-shifted by approximately $300 \mathrm{~cm}^{-1}$ compared to the corresponding six-porphyrin nanoring. Time-resolved fluorescence anisotropy measurements show that there is ultra-fast energy migration from excited states associated with the staves of the barrel to the six-porphyrin ring regions. Further studies of the electronic delocalization in the radical cations of these molecules are currently underway. We are also investigating the possibility of preparing longer nanotubes using this synthetic strategy.

Keywords: fluorescence anisotropy - nanotubes · polycycles . synthetic methods · template synthesis

How to cite: Angew. Chem. Int. Ed. 2015, 54, 7344-7348 Angew. Chem. 2015, 127, 7452-7456

[1] F. E. Golling, M. Quernheim, M. Wagner, T. Nishiuchi, K. Müllen, Angew. Chem. Int. Ed. 2014, 53, 1525-1528; Angew. Chem. 2014, 126, 1551-1554.

[2] S. Hitosugi, T. Yamasaki, H. Isobe, J. Am. Chem. Soc. 2012, 134, $12442-12445$

[3] J. Xia, M. R. Golder, M. E. Foster, B. M. Wong, R. Jasti, J. Am. Chem. Soc. 2012, 134, 19709-19715.

[4] a) T. Kawase, H. Kurata, Chem. Rev. 2006, 106, 5250-5273; b) K. Tahara, Y. Tobe, Chem. Rev. 2006, 106, 5274-5290; c) R. Gleiter, B. Esser, S. C. Kornmayer, Acc. Chem. Res. 2009, 42, $1108-1116$; d) D. Eisenberg, R. Shenhar, M. Rabinovitz, Chem. Soc. Rev. 2010, 39, 2879-2890.

[5] a) R. Gutzler, D. F. Perepichka, J. Am. Chem. Soc. 2013, 135, $16585-16594$; b) E. Kayahara, T. Iwamoto, H. Takaya, T. Suzuki, M. Fujitsuka, T. Majima, N. Yasuda, N. Matsuyama, S. Seki, S. Yamago, Nat. Commun. 2013, 4, 2694; c) K. Matsui, Y. Segawa, K. Itami, J. Am. Chem. Soc. 2014, 136, 16452-16458.

[6] A. Bachtold, C. Strunk, J.-P. Salvetat, J.-M. Bonard, L. Forró, T. Nussbaumer, C. Schönenberger, Nature 1999, 397, 673-675.

[7] S. Zaric, G. N. Ostojic, J. Kono, J. Shaver, V. C. Moore, M. S. Strano, R. H. Hauge, R. E. Smalley, X. Wei, Science 2004, 304, $1129-1131$.

[8] a) S. Iijima, T. Ichihashi, Nature 1993, 363, 603-605; b) H. Dai, Acc. Chem. Res. 2002, 35, 1035-1044; c) Y. Chen, Y. Zhang, Y. Hu, L. Kang, S. Zhang, H. Xie, D. Liu, Q. Zhao, Q. Li, J. Zhang, Adv. Mater. 2014, 26, 5898-5922.

[9] H. Omachi, T. Nakayama, E. Takahashi, Y. Segawa, K. Itami, Nat. Chem. 2013, 5, 572-576.

[10] a) L. T. Scott, E. A. Jackson, Q. Zhang, B. D. Steinberg, M. Bancu, B. Li, J. Am. Chem. Soc. 2012, 134, 107-110; b) E. H. Fort, L. T. Scott, J. Mater. Chem. 2011, 21, 1373-1381.

[11] J. R. Sanchez-Valencia, T. Dienel, O. Grönig, I. Shorubalko, A. Mueller, M. Jansen, K. Amsharov, P. Ruffieux, R. Fasel, Nature 2014, 512, $61-64$.

[12] a) M. Hoffmann, J. Kärnbratt, M.-H. Chang, L. M. Herz, B. Albinsson, H. L. Anderson, Angew. Chem. Int. Ed. 2008, 47, 4993-4996; Angew. Chem. 2008, 120, 5071-5074; b) J. K. Sprafke, D. V. Kondratuk, M. Wykes, A. L. Thompson, M. Hoffmann, R. Drevinskas, W.-H. Chen, C. K. Yong, J. Kärnbratt, J. E. Bullock, M. Malfois, M. R. Wasielewski, B. Albinsson, L. M. Herz, D. Zigmantas, D. Beljonne, H. L. Anderson, J. Am. Chem. Soc. 2011, 133, 17262-17273.

[13] J. Song, N. Aratani, H. Sinokubo, A. Osuka, J. Am. Chem. Soc. 2010, 132, $16356-16357$.

[14] C. Zhang, Q. Wang, H. Long, W. Zhang, J. Am. Chem. Soc. 2011, 133, 20995-21001. 


\section{Angewandte}

[15] a) R. F. Kelley, S. J. Lee, T. M. Wilson, Y. Nakamura, D. M Tiede, A. Osuka, J. T. Hupp, M. R. Wasielewski, J. Am. Chem. Soc. 2008, 130, 4277-4284; b) S. J. Lee, K. L. Mulfort, J. L. O'Donnell, X. Zuo, A. J. Goshe, P. J. Wesson, S. T. Nguyen, J. T. Hupp, D. M. Tiede, Chem. Commun. 2006, 4581 -4583; c) K.-T. Youm, S. T. Nguyen, J. T. Hupp, Chem. Commun. 2008, $3375-$ 3377.

[16] J. Rebek, Jr., Acc. Chem. Res. 2009, 42, 1660-1668.

[17] a) T. Yamaguchi, N. Ishii, K. Tashiro, T. Aida, J. Am. Chem. Soc. 2003, 125, 13934-13935; b) J. P. Hill, W. Jin, A. Kosaka, T. Fukushima, H. Ichihara, T. Shimomura, K. Ito, T. Hashizume, N. Ishii, T. Aida, Science 2004, 304, 1481-1483; c) T. Fukino, H. Joo, Y. Hisada, M. Obana, H. Yamagishi, T. Hikima, M. Takata, N. Fujita, T. Aida, Science 2014, 344, 499-504.

[18] G. D. Pantoş, P. Pengo, J. K. M. Sanders, Angew. Chem. Int. Ed. 2007, 46, 194-197; Angew. Chem. 2007, 119, 198-201.

[19] T. Yamaguchi, S. Tashiro, M. Tominaga, M. Kawano, T. Ozeki, M. Fujita, Chem. Asian J. 2007, 2, 468-476.

[20] I. Hijazi, T. Bourgeteau, R. Cornut, A. Morozan, A. Filoramo, J. Leroy, V. Derycke, B. Jousselme, S. Campidelli, J. Am. Chem. Soc. 2014, 136, 6348-6354.

[21] a) G. S. Wilson, H. L. Anderson, Chem. Commun. 1999, 15391540; b) T. E. O. Screen, K. B. Lawton, G. S. Wilson, N. Dolney, R. Ispasoiu, T. Goodson III, S. J. Martin, D. D. C. Bradley, H. L. Anderson, J. Mater. Chem. 2001, 11, 312-320.

[22] a) M. O. Senge, Chem. Commun. 2011, 47, 1943-1960; b) M. O. Senge, Y. M. Shaker, M. Pintea, C. Ryppa, S. S. Hatscher, A Ryan, Y. Sergeeva, Eur. J. Org. Chem. 2010, 237-258.

[23] P. N. Taylor, J. Huuskonen, G. Rumbles, R. T. Aplin, E. Williams, H. L. Anderson, Chem. Commun. 1998, 909-910.
[24] a) M. Gouterman, J. Mol. Spectrosc. 1961, 6, 138-163; b) H. L. Anderson, Chem. Commun. 1999, 2323-2330.

[25] C.-K. Yong, P. Parkinson, D. V. Kondratuk, W.-H. Chen, A. Stannard, A. Summerfield, J. K. Sprafke, M. C. O'Sullivan, P. H. Beton, H. L. Anderson, L. M. Herz, Chem. Sci. 2015, 6, 181 189.

[26] P. Parkinson, D. V. Kondratuk, C. Menelaou, J. Q. Gong, H. L. Anderson, L. M. Herz, J. Phys. Chem. Lett. 2014, 5, 4356-4361.

[27] K. Sugiura, Y. Fujimoto, Y. Sakata, Chem. Commun. 2000, 1105 1106.

[28] a) B. Valeur, M. N. Berberan-Santos, Molecular Fluorescence: Principles and Applications, 2nd ed., Wiley-VCH, Weinheim, Germany, 2012, pp. 192 - 195; b) C. Menelaou, J. ter Schiphorst, A. M. Kendhale, P. Parkinson, M. G. Debije, A. P. H. J. Schenning, L. M. Herz, J. Phys. Chem. Lett. 2015, 6, 1170-1176.

[29] a) M. C. O'Sullivan, J. K. Sprafke, D. V. Kondratuk, C. Rinfray, T. D. W. Claridge, A. Saywell, M. O. Blunt, J. N. O'Shea, P. H. Beton, M. Malfois, H. L. Anderson, Nature 2011, 469, 72-75; b) D. V. Kondratuk, L. M. A. Perdigao, M. C. O'Sullivan, S. Svatek, G. Smith, J. N. O'Shea, P. H. Beton, H. L. Anderson, Angew. Chem. Int. Ed. 2012, 51, 6696-6699; Angew. Chem. 2012, 124, 6800-6803; c) S. Liu, D. V. Kondratuk, S. A. L. Rousseaux, G. Gil-Ramírez, M. C. O'Sullivan, J. Cremers, T. D. W. Claridge, H. L. Anderson, Angew. Chem. Int. Ed. 2015, 54, 5355-5359; Angew. Chem. 2015, 127, 5445-5449.

Received: March 24, 2015

Revised: April 20, 2015

Published online: May 7, 2015 